J. EDUCATIONAL COMPUTING RESEARCH, Vol. 29(3) 297-313, 2003

\title{
ELEMENTS OF A SCIENCE OF E-LEARNING
}

\author{
RICHARD E. MAYER \\ University of California, Santa Barbara
}

\begin{abstract}
A science of e-learning involves the scientific investigation of how people learn in electronic learning environments. Three elements of a science of e-learning are: a) evidence - a base of replicated findings from rigorous and appropriate research studies; b) theory - a research-based theory of how people learn in electronic learning environments, which yields testable predictions; and c) applications - theory-based principles for how to design electronic learning environments, which themselves can be tested in research studies. This article provides examples of these three elements from a program of research on multimedia learning.
\end{abstract}

A science of e-learning involves the scientific investigation of how people learn in electronic learning environments. Three elements of a science of e-learning are: a) evidence - a base of replicated findings from rigorous and appropriate research studies; b) theory - a research-based theory of how people learn in electronic learning environments, which yields testable predictions; and c) applicationstheory-based principles for how to design electronic learning environments, which themselves can be tested in research studies. In this article, I offer a rationale for a science of e-learning and then provide examples of the three elementsevidence, theory, and applications - from our program of research on multimedia learning (Mayer, 2001, 2002). 


\section{RATIONALE FOR A SCIENCE OF E-LEARNING}

\section{Definition}

E-learning can be defined as instruction delivered via a computer that is intended to promote learning (Clark \& Mayer, 2003). This definition can be broken down into the what, how, and why of e-learning:

What. Instruction refers to content (e.g., words and pictures describing how lightning storms develop) and instructional methods (e.g., presenting words in spoken form rather than printed form). E-learning depends on instructional material being presented using effective instructional methods.

How. Delivered via a computer refers to presenting material via a computer by way of internet, intranet, CDROM, or related means. Instructional output includes images and printed words that appear on a screen, and sounds and spoken words from a speaker or headphones; learner input includes spoken words through a microphone, characters entered on a keyboard, and screen items clicked with a mouse. Thus, e-learning uses the output and input channels of computers and their peripheral devices.

Why. Intended to promote learning refers to the goal of helping to foster changes in learners' knowledge, which is reflected in changes in their performance. Thus, e-learning is intended to help people achieve learning objectives.

In sum, I use the term e-learning to refer to a kind of teaching that uses computers.

\section{Research Agenda}

Is learning in electronic environments different (or better) than learning in conventional environments (such as in a classroom or from a book)? This is a reasonable question, but this kind of question has generated a lot of controversy in the field of educational technology (Clark, 2001; Kozma, 1991; Salomon, 1979). The consensus among media researchers (see Clark, 2001) is that it is not productive to ask whether one medium (e.g., a computer) is better than another (e.g., a book), because it is the instructional method that promotes learning rather than the delivery device per se. For example, Mayer (2001) found no media effects in situations where the same instructional methods are used with books and computers. Similarly, using a computer game to teach botany, Moreno and Mayer (2002a) found that the same instructional methods that promoted learning in a desktop e-learning environment also promoted learning in an immersive virtual reality environment. Thus, the same design principles that promote learning in traditional environments are likely to promote learning in electronic environments. The consensus among media researchers is that e-learning has the potential to offer different (and perhaps better) learning opportunities only to the extent that it can enable different instructional methods (Clark, 2001). This is the premise behind my interest in simulations, games, and interactivity (although all of these 
methods are also available in "live" classroom environments). In sum, the primary question on the e-learning research agenda is not, "Do people learn better from computers?" but rather is, "Which aspects of e-learning environments help which kinds of learners to learn which kinds of knowledge?"

\section{EVIDENCE FOR A SCIENCE OF E-LEARNING}

Given the strong and growing interest in e-learning, there is a need for a solid research base - that is, a corpus of replicated findings based on rigorous and appropriate research methods. By replicated findings, I mean effects that have been found in a variety of contexts and with a variety of learners. By rigorous methods, I mean that the studies are well-designed and carefully executed. By appropriate methods, I mean that the studies are designed to answer useful research questions and test useful theoretical predictions. The methods can range from experiments to observational studies and can use quantitative or qualitative measures as long as they inform the question under study (Shavelson \& Towne, 2002).

As an example of an empirical research base, I briefly summarize some of the replicated effects that my colleagues and I at Santa Barbara have found over the last 12 years in our studies of multimedia learning (Mayer, 2001, 2002). We defined multimedia learning as learning from words and pictures. In e-learning environments, multimedia learning involves words (such as printed text presented on screen or spoken text presented via speakers) and pictures (such as animation, video, drawings, photos, and other graphics presented on screen). We focused on how to help learners understand explanations of how scientific systems work, such as how lightning storms develop, how the human respiratory system works, how a car's braking system works, how a bicycle tire pump works, how an airplane achieves lift, or how a plant grows. For example, we created short narrated animations that were presented in stand-alone form or as a part of a larger educational computer game. We measured learning via transfer tests in which learners were asked to generate as many creative answers as they could to questions that required applying the presented explanation. For example, after viewing a narrated animation explaining lightning formation, students were asked to write answers to questions such as, "What could be done to reduce the intensity of lightning storms?" or "Suppose you see clouds in the sky but no lightning. Why not?" Scientific explanations are a type of conceptual knowledge, so our study of learning was confined to one type of knowledge (Anderson et al., 2001). Transfer tests focus on the learner's ability to apply what was learned to new situations, so our study was confined to one kind of cognitive process (Anderson et al., 2001).

In a recent report on the characteristics of scientific research in education, Shavelson and Towne (2002) argue that educational research should be guided by a set of fundamental principles. My focus on "evidence" is consistent with three of the principles. The first principle proposed by Shavelson and Towne (2002, p. 3) is 
to "pose significant questions that can be investigated empirically" (Shavelson \& Towne, 2002, p. 3). In our study of multimedia learning we asked, "Do students learn a scientific explanation more deeply from words and pictures than from words alone?" and, if so, "Which aspects of a multimedia explanation promote deep learning in which learners?" By focusing on testable questions we restricted our investigation to one kind of e-learning environment (namely, multimedia learning environments), one kind of knowledge (namely, scientific explanations), and one kind of outcome test (namely, transfer tests).

A related principle is to "use methods that permit direct investigation of the question" (Shavelson \& Towne, 2002, p. 3). In our research, we relied mainly on controlled experiments because they are best suited for determining causal relations (such as being able to determine whether adding pictures to words causes students to better understand an explanation). Informal methods, including openended interviews with learners, also were used in some pilot work to gain insights into how individual learners sought to make sense of the explanations.

Finally, another related principle is to "replicate and generalize across studies" (Shavelson \& Towne, 2002, p. 4). Each of the nine major findings I report in this article has been found in at least two independent studies, and some in as many as 12 .

The result of our evidence seeking efforts is a collection of nine major effects based on dozens of studies: modality effect, contiguity effect, multimedia effect, personalization effect, coherence effect, redundancy effect, pretraining effect, signaling effect, and pacing effect. These replicated effects are summarized in Table 1.

\section{Modality Effect}

When presenting a multimedia explanation consisting of an animation and corresponding verbal explanation, does it matter whether the words are spoken (as narration) or printed (as on-screen text)? In 12 separate experimental comparisons involving multimedia explanations of lightning (Mayer \& Moreno, 1998, Experiment 1; Moreno \& Mayer, 1999a, Experiments 1 and 2) and brakes (Mayer \& Moreno, 1998, Experiment 2) or educational games about plant growth (Moreno \& Mayer, 2002a, Experiments 1, 2, and 3; Moreno, Mayer, Spires, \& Lester, 2001, Experiments 4a, 4b, 5a, 5b) or aircraft fuel systems (O’Neil, Mayer, Herl, Thurman, \& Olin, 2000, Experiment 1), students who received animation and narration performed better on transfer tests than did students who received animation and on-screen text. We refer to this pattern as the modality effect.

\section{Contiguity Effect}

When presenting a multimedia explanation consisting of an animation depicting how something works and a narration describing how something works, does it matter whether corresponding segments of the animation and narration are 
Table 1. Some Replicated Effects in Multimedia Learning

\begin{tabular}{|c|c|c|}
\hline Name and description & $\begin{array}{l}\text { Number } \\
\text { of tests }\end{array}$ & $\begin{array}{l}\text { Effect } \\
\text { size }\end{array}$ \\
\hline $\begin{array}{l}\text { Modality effect: Better transfer from animation and } \\
\text { narration than for animation and on-screen text. }\end{array}$ & 12 of 12 & 1.13 \\
\hline $\begin{array}{l}\text { Contiguity effect: Better transfer when corresponding } \\
\text { narration and animation are presented simultaneously } \\
\text { rather than successively. }\end{array}$ & 8 of 8 & 1.30 \\
\hline $\begin{array}{l}\text { Multimedia effect: Better transfer from animation and } \\
\text { narration rather than narration alone. }\end{array}$ & 5 of 5 & 1.67 \\
\hline $\begin{array}{l}\text { Personalization effect: Better transfer when narration is } \\
\text { in conversational style rather than formal style. }\end{array}$ & 5 of 5 & 1.55 \\
\hline $\begin{array}{l}\text { Coherence effect: Better transfer when irrelevant video, } \\
\text { narration, and sounds are excluded rather than included. }\end{array}$ & 3 of 3 & 0.96 \\
\hline $\begin{array}{l}\text { Redundancy effect: Better transfer from animation and } \\
\text { narration than from animation, narration, and on-screen text. }\end{array}$ & 3 of 3 & 0.84 \\
\hline $\begin{array}{l}\text { Pretraining effect: Better transfer when training on compo- } \\
\text { nents precedes rather than follows a narrated animation. }\end{array}$ & 3 of 3 & 1.39 \\
\hline $\begin{array}{l}\text { Signaling effect: Better transfer when narrations are } \\
\text { signaled rather than non-signaled. }\end{array}$ & 2 of 2 & 0.60 \\
\hline $\begin{array}{l}\text { Pacing effect: Better transfer when the pace of presentation } \\
\text { is under learner control rather than program control. }\end{array}$ & 2 of 2 & 1.03 \\
\hline
\end{tabular}

Note: Effect size was computed by subtracting the mean of the control group from the mean of the experimental group and dividing the result by the standard deviation of the control group. Median effect size is reported in column 3.

presented at the same time? In eight separate experiments involving multimedia explanations of pumps (Mayer \& Anderson, 1991, Experiments 1 and 2; Mayer \& Anderson, 1992, Experiment 1), brakes (Mayer \& Anderson, 1992, Experiment 2; Mayer \& Sims, 1994, Experiment 1; Mayer Moreno, Boire, \& Vagge, 1999, Experiment 2), lightning (Mayer et al., 1999, Experiment 1), or lungs (Mayer \& Sims, 1994, Experiment 2), students who received corresponding segments of the animation and narration at the same time performed better on transfer tests than did students who received the entire narration either before or after 
the animation. We refer to this pattern as the contiguity effect (or temporal contiguity effect).

\section{Multimedia Effect}

When presenting a scientific explanation of how something works using words, does it help to add corresponding pictures depicting how it works? In five separate experiments involving multimedia explanations of pumps (Mayer \& Anderson, 1991, Experiment 2a; Mayer \& Anderson, 1992, Experiment 1), brakes (Mayer \& Anderson, 1992, Experiment 2), or lightning (Moreno \& Mayer, 2002a, Experiment 1), or an educational game involving arithmetic (Moreno \& Mayer, 1999b, Experiment 1), students who received corresponding animation and narration presented at the same time performed better on transfer tests than did students who received only the narration. We refer to this pattern as the multimedia effect.

\section{Personalization Effect}

When presenting a scientific explanation of how something works using animation and narration, does it help to present the narration in conversational style rather than formal style? In five separate experiments involving multimedia explanations of lighting (Moreno \& Mayer, 2000a, Experiments 1 and 2), or an educational game involving plant growth (Moreno \& Mayer, 2000a, Experiments 3,4 , and 5), students who received conversational narration performed better on transfer tests than did students who received formal narration. We refer to this pattern as the personalization effect.

\section{Coherence Effect}

When presenting a scientific explanation of how something works using animation and narration, does it help to add interesting material such as music and video? In three separate experiments involving multimedia explanations of lightning (Mayer, Heiser, \& Lonn, 2001, Experiment 1; Moreno \& Mayer, 2000b, Experiment 1) or brakes (Moreno \& Mayer, 2000b, Experiment 2), students who received animation and narration performed better on transfer tests than did students who received animation and narration along with background music and sounds or along with interesting video clips. We refer to this pattern as the coherence effect.

\section{Redundancy Effect}

When presenting a scientific explanation of how something works using animation and narration, does it help to add redundant on-screen text? In three separate experiments involving multimedia explanations of lightning (Mayer, Heiser, \& Lonn, 2001, Experiments 1 and 2; Moreno \& Mayer, 2002b, Experiment 2 ), students who received animation and narration performed better on transfer 
tests than did students who received animation, narration, and on-screen text. We refer to this pattern as the redundancy effect.

\section{Pretraining Effect}

When presenting a scientific explanation of how something works using animation and narration, is it better to provide an explanation of components before or after the presentation? In three separate experiments involving multimedia explanations of lightning (Mayer \& Chandler, 2001, Experiment 1), brakes (Mayer, Mathias, \& Wetzell, 2002, Experiment 2), and pumps (Mayer, Mathias, \& Wetzell, 2002, Experiment 3), students who received component explanations before the presentation performed better on transfer tests than did students who received the component explanations after the presentation. We refer to this pattern as the pretraining effect.

\section{Signaling Effect}

When presenting a scientific explanation of how something works using animation and narration, is it better to include signals in the narration that emphasize the organization of the material? The signals include a preview sentence that lists the main sections of the presentation, and headings stated in a deeper voice that introduce each section of the presentation. In two separate experimental tests involving multimedia explanations of airplane lift (Mautone \& Mayer, 2001, Experiments 3a and 3b), students who received signaled narration performed better on transfer tests than did students who received non-signaled narration. We refer to this pattern as the signaling effect.

\section{Pacing Effect.}

When presenting a scientific explanation of how something works using animation and narration, is it better to allow learners to control the pace of presentation? In two separate experiments involving multimedia explanations of lightning Mayer \& Chandler, 2001, Experiment 1) and how an electric motor works (Mayer, Dow, \& Mayer, in press, Experiment 2), students who were able to press a "CONTINUE" button to go on to the next segment performed better on transfer tests than did students who received the narrated animation as a continuous presentation. We refer to this pattern as the pacing effect.

In short, based on dozens of research studies conduced over a span of 12 years, we have been able to establish a core of replicated findings corresponding to the requirement for evidence in a science of e-learning. Although the evidence in Table 1 is based on transfer tests, similar patterns have been obtained on retention tests (Mayer, 2001). Although my focus is on reviewing research from our lab, similar evidence has been reported by many other researchers around the world, most notably Sweller (1999) and his colleagues. Evidence is needed to test 
theories (as shown in the next section on theory) and to ground applications (as shown in the section on applications).

\section{THEORY FOR A SCIENCE OF E-LEARNING}

An empirical research base is a necessary but not sufficient ingredient in the recipe for a science of e-learning. In their analysis of the principles of scientific research in education, Shavelson and Towne (2002, pp. 3-4) describe two principles concerning the role of theory: "link research to theory" and "provide a coherent and explicit chain of reasoning."

In our research on multimedia learning, we developed and tested a cognitive theory of multimedia learning that is based on three basic ideas from researchbased theories in cognitive science: dual channels, limited capacity, and knowledge construction. First, humans are dual-channel processors; that is, people have separate channels for processing visual/pictorial information and auditory/verbal information (Baddeley, 1999; Paivio, 1986). Second, humans are limited capacity processors, that is people are able to actively process only a small amount of information in each channel at any one time (Baddeley, 1999; Sweller, 1999). Third, humans are knowledge constructing processors, so meaningful learning occurs when people attend to relevant incoming information, mentally organize the information in coherent structures, and mentally integrate it with other knowledge (Mayer, 2003; Wittrock, 1989).

Figure 1 presents a cognitive theory of multimedia learning consisting of two channels - an auditory/verbal channel in the top row and a visual/pictorial channel in the bottom row. When a learner sits in front of a computer screen and receives a multimedia presentation, words and pictures are presented (as indicated in the first column). Spoken words impinge on the learner's ears while printed words and pictures impinge on the learner's eyes (as indicated in the second column). If the learner pays attention (indicated by the "selecting words" and "selecting images" arrows, respectively) some of the incoming words are represented in the learner's working memory as sounds in the learner's working memory, and some of the incoming pictures or printed words are represented as images in the learner's working memory (as shown in the third column). If the learner mentally organizes the sounds into a coherent representation (as indicated by the "organizing words" arrow) and mentally organizes the images into a coherent representation (as indicated by the "organizing images" arrow), the result is the construction of verbal and pictorial models in working memory (as indicated by the fourth column). An integrated learning outcome is produced when the learner makes connections between the verbal and pictorial models and with prior knowledge (as indicated by the "integrating" arrows). The process of meaningful learning from multimedia involves five cognitive processes: selecting words, selecting images, organizing words, organizing images, and integrating. Meaningful learning is more likely to occur when the e-learning environments enables the 


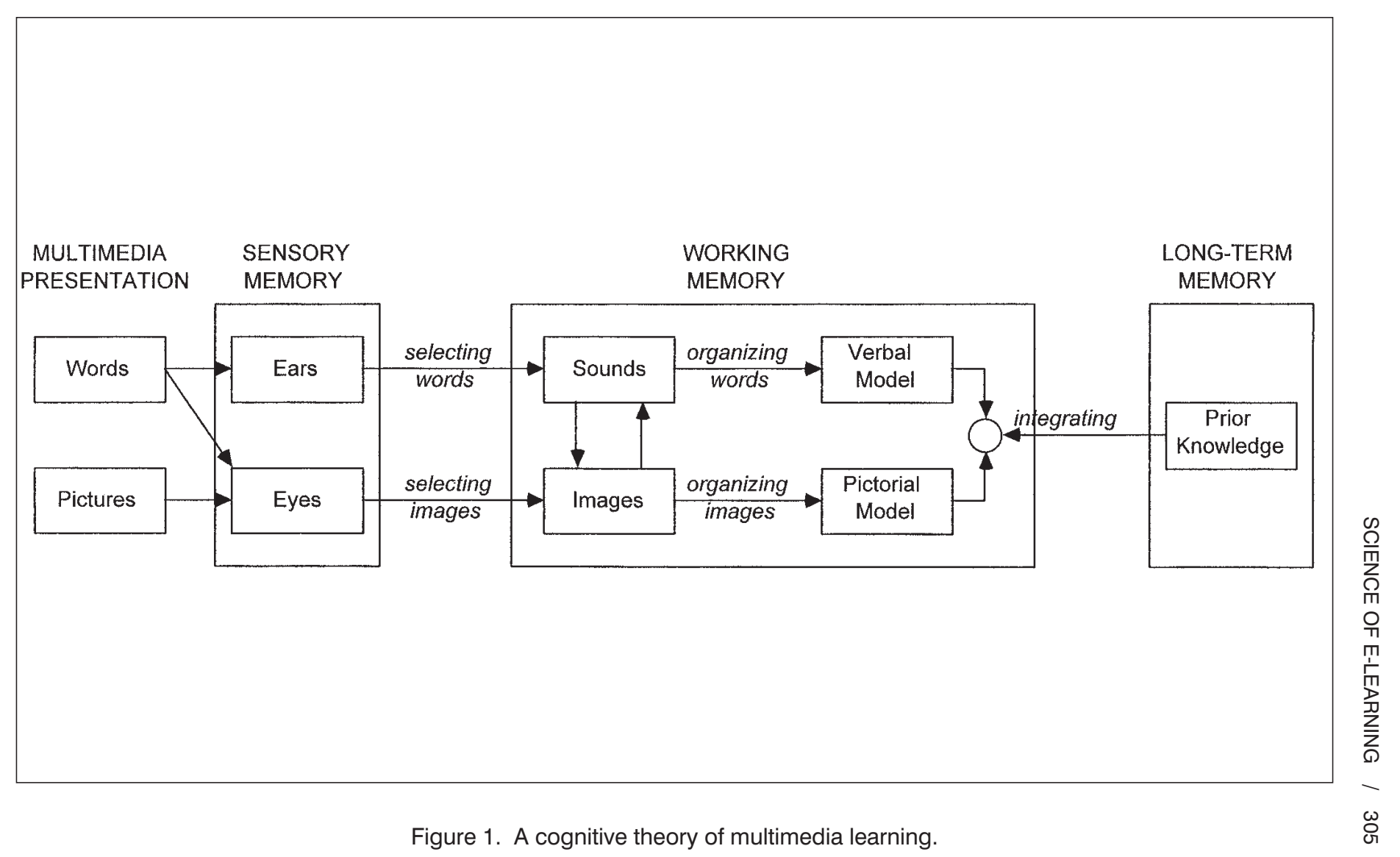


learner to engage in these five processes. Overall, the theory is intended to guide the design of instructional messages presented in computer-based environments.

The next step is to examine each of the nine effects with respect to the cognitive theory of multimedia learning. How does the cognitive theory of multimedia learning relate to the nine effects described in the previous section? In particular, does the theory help to explain the effects? In the remainder of this section, I address these questions.

\section{Modality Effect}

First, consider the situation in Figure 1 when a multimedia presentation consists of animation and concurrent on-screen text. All of the presented material is processed in the visual channel, at least initially, so it is likely that the visual channel will become overloaded. When the learner is looking at the animation, the learner may miss information in the on-screen text; when the learner is looking at the on-screen text, the learner may miss information in the animation. Thus, the learner may fail to select some important images for further processing in working memory. In contrast, consider the situation when a multimedia presentation consists of animation and concurrent narration. The animation can be processed in the visual channel while the narration is processed in the verbal channel, thus offloading some of the demands on the visual channel. In this case, the learner is better able to select relevant images and sounds for further processing in working memory. Thus, the cognitive theory of multimedia learning predicts deeper learning with animation and narration than from animation and on-screen text. This is the pattern we found across 12 separate experimental tests.

\section{Contiguity Effect}

First, consider the situation in Figure 1 when a multimedia presentation consists of a narration followed by a corresponding animation (or vice versa). In successive presentation, the learner's working memory does not have the capacity to hold the entire animation in working memory until the narration is presented (or vice versa). Thus, in the successive presentation method, the learner is not able to hold corresponding verbal and pictorial representations in working memory at the same time (such as a mental image of negative particles falling to the bottom of a cloud along with spoken words "negative particles fall to the bottom of the cloud"), and therefore is less likely to engage in the cognitive process of integration. Now, consider what happens when the narration and animation are presented simultaneously so that the words in the narration describe the same thing as is being depicted in the animation. In this situation, the learner is more likely to be able to hold corresponding verbal and pictorial representations in working memory at the same time, and therefore, is more likely to engage in the process of integration. Thus, the theory predicts deeper learning when the animation and 
narration are presented simultaneously rather than successively. This prediction was supported in eight experimental tests.

\section{Multimedia Effect}

When only narration is presented, the learner is likely to construct a verbal model, as indicated in Figure 1, but may not be able to form a corresponding pictorial model. When both narration and animation are presented, the learner can construct representations in both channels, resulting in corresponding verbal and pictorial representations. Thus, the learner is more likely to be able to integrate verbal and pictorial models - and thereby engage in deeper learning - when the presentation consists of narration and animation rather than narration alone. Although all forms of verbal-pictorial integration may not result in deeper learning, in Figure 1 the focus is on integrating verbal and pictorial models of a system - a cognitive process enabled by some types of multimedia presentation and that we predict results in deeper learning. This prediction was supported in five experimental tests.

\section{Personalization Effect}

Sometimes a new piece of evidence, such as the personalization effect, requires an extension of a proposed theory. Our working hypothesis is that using words like "you" and "I" prime a conversational schema in learners, causing them to work harder to understand what the narrator is saying. Thus, we can predict that conversational style motivates the learner to engage in the five cognitive processes shown in Figure 1, which results in deeper learning. This prediction was upheld in five experimental tests.

\section{Coherence Effect}

A theory can be useful when it conflicts with what seems like common sense. A common-sense theory of motivation would predict that making a presentation more interesting — such as by adding some eye-grapping video or background music - would cause the learner to work harder and thus result in deeper learning. In contrast, based on the cognitive theory of multimedia learning summarized in Figure 1, adding video or music could distract the learner so attention is paid to irrelevant material (indicated in the "selecting words" and "selecting images" arrows), could disrupt the organizing process of building a model (indicated in the "organizing words" and "organizing images" arrows) by putting extraneous material between the links in the cause-and-effect chain, and could disorient the learner by priming inappropriate prior knowledge (as indicated by the "integrating" arrow). Thus, the cognitive theory of multimedia learning predicts that eliminating interesting but irrelevant material will result in deeper learning. This prediction was upheld in three experimental tests. 


\section{Redundancy Effect}

Another common-sense theory holds that information should be presented in as many formats as possible so learners can choose the format best suited to their needs. According to this information delivery view, students should learn better from animation, narration, and on-screen text than from animation and narration alone. In contrast, the cognitive theory of multimedia learning predicts that adding redundant on-screen text to animation and narration will hurt the process of learning for the same reasons described in the section on the modality effect- - the visual channel may become overloaded by processing animation and on-screen text. This prediction was upheld in three experimental tests.

\section{Pretraining Effect}

Our research focuses on explaining how a cause-and-effect system works, so learners must understand how each component works (i.e., build component models) and must understand how the entire system works such that a change in one component causes a change in another and so on (i.e., build a cause-and-effect system model). When a narrated animation is presented, the learner must try to construct both kinds of models at one time, which may be so demanding that it can overload the capacity of working memory. It would be easier to build a system model from the multimedia presentation, if the learner already knew what each component does, so we can predict that students learn more deeply from a multimedia presentation if they have received pretraining in the components. If they are given the component training after the multimedia presentation, that will be too late to reduce cognitive load during learning from the multimedia presentation. In three experimental tests, these predictions were supported.

\section{Signaling Effect}

Another way to reduce cognitive load in the verbal channel is to use signalingcues for the learner about how to organize the material. The cognitive theory of multimedia learning predicts that signaling will assist learners in the process of organizing sounds, and thus result in deeper learning. This prediction was supported in two experimental tests.

\section{Pacing Effect}

Learners require some time to engage in the cognitive processes of selecting, organizing, and integrating incoming information. If the pace of presentation is too fast, the processes may have to cut short, resulted in poorer learning. When the learner can control the pace of presentation, such as by clicking a "CONTINUE" button after each segment of the presentation, the learner is more likely to be able to engage in complete cognitive processing and thus deeper learning. This prediction was supported in two experimental tests. 
Although we have focused on our proposed theory of multimedia learning, similar predictions could also be derived for other models (Schnotz, 2002; Sweller, 1999).

\section{APPLICATIONS FOR A SCIENCE OF E-LEARNING}

So far I have shown the role of evidence- a corpus of replicated findingsand theory - a model that explains the findings - in a science of e-learning. The third component is applications - being able to relate the evidence and theory to practical e-learning situations (Clark, 1999). The applications component of a science of e-learning is related to the sixth and final principle of scientific research in education proposed by Shavelson and Towne (2002, p. 5): "disclose research to encourage professional scrutiny and critique." Consistent with this principle, we have published reports of our research in multimedia learning in primary research journals and at professional conferences, and have provided summaries of our research in books and chapters (e.g., Mayer, 2001, 2002).

In many ways, the true test of a theory is whether it works in the real world, so we have been eager to suggest design principles for multimedia instruction based on our research. Table 2 lists nine principles for practice that follow from our research program. A more complete review of the practical implications of our research can be found in Clark and Mayer's (2003) e-Learning and the Science of Instruction.

Do the principles listed in Table 2 work? This is an important question that warrants further investigation. For example, several educational researchers (Levin \& O’Donnell, 1999; Slavin, 2002) argue for controlled experimental field tests similar to clinical trials used in medicine. In a controlled experimental field test (or clinical trial) some students in a natural setting would be randomly assigned to receive training based on the principles (experimental treatment) or equivalent training not based on the principles (control treatment). If the experimental treatment results in better performance on a test of learning, then we would have both practical support and theoretical support for our principles of multimedia design. Such field research would complement the research method used in our research - mainly, lab-based studies comparing treatment and control groups. In short, the challenge of evidence-based practice completes the picture for a science of e-learning.

The history of educational technology is replete with examples of grand claims for how some new technology would revolutionize education, but when the technologies were implemented in schools the results were disappointing (Cuban, 1986, 2001). In order to avoid more unfulfilled promises about educational technologies, it is worthwhile to connect applications with evidence and theory. Although we have offered research-based principles, there is a need for the kind of controlled field test described in this section. 


\section{CONCLUSION}

An important challenge for educational computing researchers is the construction of a science of e-learning. A science of e-learning depends on: 1) evidence - a core of replicated findings, such as the design effects listed in Table 1 for multimedia learning; 2) theory-a research based model of how people learn in electronic environments, such as the cognitive theory of multimedia learning summarized in Figure 1; and 3) applications - theory-based principles for the design of e-learning environments, such as the design principles for multimedia learning suggested in Table 2. As the study of e-learning moves beyond the confines of multimedia messages about how things work, the same three elements are required-evidence, theory, and applications.

Table 2. Some Design Principles for the Design of Multimedia Explanations

Principle

Modality principle: When designing a multimedia explanation, present the words in spoken form.

Contiguity principle: When designing a multimedia explanation, present corresponding words and pictures at the same time.

Multimedia principle: When designing a computer-based explanation, use both words and pictures.

Personalization principle: When designing a multimedia explanation, present words in conversational style.

Coherence principle: When designing a multimedia explanation, avoid extraneous video and audio.

Redundancy principle: When designing a multimedia explanation involving animation and narration, do not add redundant on-line text.

Pretraining principle: When designing a multimedia explanation, begin the presentation with concise descriptions of the components.

Signaling principle: When designing a multimedia explanation, provide signaling for the narration.

Pacing principle: When designing a multimedia explanation, allow the learner to have control over the pace of presentation. 
What happens when elements are missing from a science of e-learning? Seeking evidence without theory is blind empiricism - resulting in a disorganized collection of random facts. Building theory without evidence is blind speculationresulting in opinions that are not warranted by scientific testing. Offering recommendations for application without evidence and theory is blind advocacyresulting in a fad-based approach to practice. Seeking evidence and theory without an eye toward applications is invalid science-resulting in investigations that fail to make contact with the real world. The study of e-learning is an exciting venue because the three elements of science seem to fit together so seamlessly, as is exemplified by our research program on multimedia learning. To the extent that our field can coordinate evidence, theory, and applications, there is reason for optimism.

\section{REFERENCES}

Anderson, L. W., Krathwohl, D. R., Airasian, P. W., Cruikshank, K. A., Mayer, R. E., Pintrich, P. R., Raths, J., \& Wittrock, M. C. (2001). A taxonomy for learning, teaching, and assessing. New York: Longman.

Baddeley, A. (1999). Human memory. Boston: Allyn \& Bacon.

Clark, R. C. (1999). Developing technical training (2nd ed). Washington, DC: International Society for Performance Improvement.

Clark, R. C., \& Mayer, R. E. (2003). e-learning and the science of instruction. San Francisco: Jossey-Bass.

Clark, R. E. (Ed.) (2001). Learning from media. Greenwich, CT: Information Age Publishing.

Cuban, L. (1986). Teachers and machines: The classroom use of technology since 1920. New York: Teachers College Press.

Cuban, L. (2001). Oversold and underused: Computers in the classroom. Cambridge, MA: Harvard University Press.

Kozma. R. B. (1991). Learning with media. Review of Educational Research, 61, 179-211.

Levin, J. R., \& O'Donnell, A. (1999). What to do about educational research's credibility gaps? Issues in Education, 5, 177-239.

Mautone, P. D. , \& Mayer, R. E. (2001). Signaling as a cognitive guide in multimedia learning. Journal of Educational Psychology, 93, 377-389.

Mayer, R. E. (2001). Multimedia learning. New York: Cambridge University Press.

Mayer, R. E. (2002). Multimedia learning. In B. H. Ross (Ed.), The psychology of learning and motivation (Vol. 41, pp. 85-139). San Diego: Academic Press.

Mayer, R. E. (2003). Learning and instruction. Upper Saddle River, NJ: Prentice Hall.

Mayer, R. E., \& Anderson, R. B. (1991). Animations need narrations: An experimental test of a dual-coding hypothesis. Journal of Educational Psychology, 83, 484-490.

Mayer, R. E., \& Anderson, R. B. (1992). The instructive animation: Helping students build connections between words and pictures in multimedia learning. Journal of Educational Psychology, 84, 444-452. 
Mayer, R. E., \& Chandler, P. (2001). When learning is just a click away: Does simple user interaction foster deeper understanding of multimedia messages? Journal of Educational Psychology, 93, 390-397.

Mayer, R. E., Dow, G. T., \& Mayer, S. (in press). Teaching students to solve insight problems: Evidence for domain specificity. Journal of Educational Psychology.

Mayer, R. E., Heiser, J., \& Lonn, S. (2001). Cognitive constraints on multimedia learning: When presenting more material results in less learning. Journal of Educational Psychology, 93, 187-198.

Mayer, R. E., Mathias, A., \& Wetzell, K. (2002). Fostering understanding of multimedia messages through pretraining: Evidence for a two-stage theory of mental model construction. Journal of Experimental Psychology: Applied, 8, 147-154.

Mayer, R. E., \& Moreno, R. (1998). A split-attention effect in multimedia learning: Evidence for dual processing systems in working memory. Journal of Educational Psychology, 90, 312-320.

Mayer, R. E., Moreno, R., Boire, M., \& Vagge, S. (1999). Maximizing constructivist learning from multimedia communications by minimizing cognitive load. Journal of Educational Psychology, 91, 638-643.

Mayer, R. E., \& Sims, V. K. (1994). For whom is a picture worth a thousand words? Extensions of a dual-coding theory of multimedia learning. Journal of Educational Psychology, 84, 389-401.

Moreno, R., \& Mayer, R. E. (1999a). Cognitive principles of multimedia learning: The role of modality and contiguity. Journal of Educational Psychology, 91, 358-368.

Moreno, R., \& Mayer, R. E. (1999b). Multimedia-supported metaphors for meaning making in mathematics. Cognition and Instruction, 17, 215-248.

Moreno, R., \& Mayer, R. E. (2000a). Engaging students in active learning: The case for personalized multimedia messages. Journal of Educational Psychology, 92, 724-733.

Moreno, R., \& Mayer, R. E. (2000b). A coherence effect in multimedia learning: The case for minimizing irrelevant sounds in the design of multimedia instructional messages. Journal of Educational Psychology, 92, 117-125.

Moreno, R., \& Mayer, R. E. (2002a). Learning science in virtual reality environments: Role of method and media. Journal of Educational Psychology, 94, 598-610.

Moreno, R., \& Mayer, R. E. (2002b). Verbal redundancy in multimedia learning: When reading helps listening. Journal of Educational Psychology, 94, 156-163.

Moreno, R., Mayer, R. E., Spires, H., \& Lester, J. (2001). The case for social agency in computer-based teaching: Do students learn more deeply when they interact with animated pedagogical agents? Cognition and Instruction, 19, 177-214.

O’Neil, H. F., Jr., Mayer, R. E., Herl, H., Thurman, R., \& Olin, K. (2000). Instructional strategies for virtual environments. In H. F. O’Neil \& D. H. Andrews (Eds.), Aircraft training: Methods, technologies, and assessment (pp. 105-130). Mahwah, NJ: Erlbaum.

Paivio, A. (1986). Mental representations: A dual coding approach. Oxford, UK: Oxford University Press.

Schnotz, W. (2002). Towards an integrated view of learning from text and visual displays. Educational Psychology Review, 14, 101-120.

Shavelson, R. J., \& Towne, L. (2002). Scientific research in education. Washington, DC: National Academy Press.

Slavin, R. E. (2002). Evidence-based education policies: Transforming educational practice and research. Educational Researcher, 31, 15-31. 
Salomon, G. (1979). Interaction of media, cognition, and learning. San Francisco: Jossey-Bass.

Sweller, J. (1999). Instructional design in technical areas. Camberwell, Australia: ACER Press.

Wittrock, M. C. (1989). Generative processes of comprehension. Educational Psychologist, 24, 345-376.

Direct reprint requests to:

Dr. Richard E. Mayer

Department of Psychology

University of California

Santa Barbara, CA 93106-9660

e-mail: mayer@psych.ucsb.edu 